\title{
CONTEÚdOS DE MATEMÁTICA DO ENSINO MÉDIO NOS LIVROS DE MINICURSOS DA SBHMat (2001-2017)
}

\author{
CONTENTS OF MATHEMATICS OF TEACHING MEDIUM IN THE BOOKS OF \\ MINICURES OF SBHMat (2001-2017)
}

Iran Abreu Mendes ${ }^{1}$

Orcid: 0000-0001-7910-1602

Lucas Silva Pires ${ }^{2}$

Orcid: $\underline{0000-0002-8365-9788}$

\begin{abstract}
RESUMO
O presente artigo tem como objeto de investigação os livros de minicursos da Sociedade Brasileira de História da Matemática (SBHMat), que foram produzidos para publicação nos Seminários Nacionais de História da Matemática (SNHM) entre 2001 e 2017. O nosso objetivo foi caracterizar os conteúdos de Matemática do Ensino Médio nos livros de minicursos, classificados com tendência em História para o Ensino da Matemática (HEnM), organizados no Centro Brasileiro de Referência em Pesquisa sobre História da Matemática (CREPHIMat). O fundamento epistemológico de sustentação do artigo assentase em uma noção conceitual basilar estabelecida por Mendes (2017, 2020) e Barros e Mendes (2017, 2019). Para definirmos os livros de minicursos, adotamos um instrumento de análise elaborado a partir dos estudos relativos à ciência da documentação. Posteriormente, selecionamos e descrevemos os conteúdos de Matemática do Ensino Médio. Os resultados indicaram que os temas abordados possuem potencialidade didática e podem ser explorados por professores que atuam no Ensino Médio, com vistas a enriquecer o ensino e aprendizagem em Matemática dos alunos desse nível de instrução.
\end{abstract}

Palavras-chave: História para o Ensino da Matemática. Livros de Minicursos da SBHMat. Conteúdos de Matemática do Ensino Médio.

\begin{abstract}
Our objective was to characterize the contents of High School Mathematics in short course books classified in the trend in History for the Teaching of Mathematics (HEnM), organized at the Brazilian Center for Reference in Research on the History of Mathematics (CREPHIMat). The epistemological basis for supporting the article is based on a basic conceptual notion established by Mendes $(2017,2020)$ and Barros and Mendes $(2017,2019)$. In order to characterize the short course books, we adopted an analysis instrument based on studies related to documentation science. Subsequently, we selected and described the high school mathematics content. The results indicated that the contents covered have didactic potential and can be explored by teachers working in high school, in order to enrich the teaching and learning in mathematics of students at this level of education.
\end{abstract}

\footnotetext{
${ }^{1}$ Doutor em Educação pela Universidade Federal do Rio Grande do Norte (UFRN). Professor Titular Livre do Programa de Pós-graduação em Educação em Ciências e Matemáticas do Instituto de Educação Matemática e Científica da Universidade Federal do Pará, Belém, Pará, Brasil. Endereço para correspondência: Travessa Padre Eutíquio 2564, Ap. 2001. Batista Campos, Belém, Pará, Brasil, 66033728. E-mail: iamendes1@ gmail.com.

${ }^{2}$ Mestre em Ciências e Educação Matemática pela Universidade Federal do Pará (UFPA). Professor de Matemática da Educação Básica da E.M.E.F. Prof ${ }^{\circ}$ Hélio Frota Lima, Abel Figueiredo, Pará, Brasil. Endereço para correspondência: TV. Rua Nossa Senhora da Conceição, Centro, número 259, Abel Figueiredo, Pará, Brasil, 68527000. E-mail: lucas.silvapires.10@gmail.com.
} 
Keywords: History for the Teaching of Mathematics. SBHMat Short Course Books. High School Mathematics Contents.

\section{CONSIDERAÇÕES INICIAIS}

Neste $\operatorname{artigo}^{3}$, focamos como objeto de investigação os livros de minicursos produzidos sob a chancela da Sociedade Brasileira de História da Matemática (SBHMat) ${ }^{4}$, que foram elaborados para publicação nos Seminários Nacionais de História da Matemática (SNHM) entre 2001 e 2017. O nosso objetivo foi caracterizar os conteúdos de Matemática do Ensino Médio presentes nos livros de minicursos que foram classificados na tendência História para o Ensino da Matemática (HEnM), os quais estão organizados no Centro Brasileiro de Referência em Pesquisa sobre História da Matemática (CREPHIMat).

O CREPHIMat se constitui em um Centro Virtual que disponibiliza as produções de pesquisas em História da Matemática no Brasil, dentre outras informações e materiais sobre essa temática. O CREPHIMat, por um lado, concebe-se como um repositório digital para organizar e disponibilizar à comunidade acadêmica o maior acervo digital de produções acadêmico-científicas sobre História da Matemática no Brasil, bem como de ser também um espaço de colaboração com a comunidade acadêmica, de maneira que se possa dar sugestões didáticas e orientações a alunos, professores e pesquisadores, seja para o ensino da Matemática, por meio dos arquivos disponibilizados, fontes de consulta, ou para a pesquisa de História da Matemática em geral e nas suas tendências. Em um futuro próximo, pretende-se que o referido local da web possa promover seminários e cursos a distância sobre a temática ou mesmo alguns ateliês de pesquisa nesse campo (CREPHIMat, 2020, p. online).

Nesse sentido, a ação empreendida no estudo que originou este artigo se ancorou na importância da caracterização dos conteúdos de Matemática tratados nos livros de minicursos, por considerar que, ao serem selecionados e descritos pormenorizadamente, poderão favorecer a prática do professor durante o exercício da docência, pois pesquisas apontam que o uso da História para o ensino da Matemática pode favorecer a aprendizagem dos alunos, bem como despertar habilidades que estiverem subjacentes, dentre as quais destacamos a motivação

\footnotetext{
${ }^{3}$ Este artigo foi elaborado a partir de uma Comunicação Científica que apresentamos no Seminário de Cognição e Educação Matemática (SCEM) que aconteceu no ano de 2019, em Belém, Pará, Brasil.

${ }^{4}$ Os livros de minicursos da SBHMat são um dos objetos de investigação vinculados a dois projetos coordenados pelo professor Doutor Iran Abreu Mendes e financiados pelo Conselho Nacional de Desenvolvimento Científico e Tecnológico (CNPq), intitulados História para o Ensino de Matemática na Formação de Professores e na Educação Básica: uma análise da Produção Brasileira entre 1990 a 2017 e Uma história das pesquisas em História da Matemática no Brasil: produções, disseminações e contribuições à Formação de Professores de Matemática.
} 
cognitiva, o espírito crítico, a tomada de decisões e a apropriação consistente pelo domínio conceitual do objeto matemático.

O estudo está embasado em uma noção conceitual basilar estabelecida por Mendes (2017, 2020), história para o ensino da Matemática como uma reinvenção didática para sala de aula, ao tecer argumentos que nos possibilitaram compreender sistematicamente que a História com fins pedagógicos e didáticos não é aquela com enfoque sobre locais em que renomados matemáticos nasceram e trabalharam, ou aquela rodeada de acessórios e ornamentos, mas a que tem por vocação e preocupação os conhecimentos matemáticos, podendo ser favorável à inserção desse ensino em sala de aula. Em outras palavras, refere-se às histórias no plural, isto é, àquelas que estão conectadas, integradas ou mesmo tecidas em meio a outras histórias das mais diversas qualidades. Logo, podemos considerar que se trata de histórias sobre as produções de ideias matemáticas e suas materializações em múltiplas linguagens representativas. Talvez, também seja dessa multiplicidade que surge a característica plural dessas histórias.

Igualmente, levamos em conta, também, as considerações apresentadas por Barros e Mendes (2017, 2019), quando referem-se aos potenciais didáticos para a sala de aula, identificados nas pesquisas em história da matemática, que contêm informações históricas potentes para uma reorganização conceitual na forma de encaminhamentos didáticos que possam ser inseridos na prática docente. Para tanto, os autores argumentam que os alunos devem compreender o processo de construção da Matemática em cada contexto e momento histórico específico.

O estudo se relaciona, ainda, com um levantamento desenvolvido por Mello (2012) em sua dissertação de mestrado, que catalogou teses e dissertações sobre História da Matemática a partir de três modalidades classificadas por Mendes (2012) como: 1) História e Epistemologia da Matemática, a qual tratou do desenvolvimento epistemológico de uma teoria ou de um conceito matemático e do desenvolvimento de um tema específico da Matemática, bem como vida e obras de matemáticos, sobre as ideias matemáticas produzidas ao longo da história da humanidade; 2) História para o Ensino da Matemática, a qual se caracteriza pela preocupação com fins pedagógicos como elaboração de materiais didáticos para ensinar Matemática, usando fragmentos da História da Matemática, os quais podem ser utilizados, tanto na elaboração de materiais didáticos para dar subsídios aos professores em sala de aula, como também, materiais que trataram de orientar o professor sobre a forma como utilizar fontes históricas para ensinar matemática, bem como para a formação de professores que ensinam matemática em diversos níveis de ensino e 3) História da Educação Matemática, a qual trata de biografias de 
matemáticos tanto dos antigos, como dos atuais, da história de instituições, história e memória, história oral, história de cursos, entre outros aspectos (MENDES, 2014, 2015).

Nesse sentido, a dissertação de Gonçalves (2015) faz um movimento em que focaliza teses e dissertações que trataram da História da Educação Matemática e busca identificar e analisar os potenciais didáticos contidos nesses trabalhos visando estabelecer encaminhamentos conceituais e didáticos para o uso dessas informações históricas na docência em classes da Educação Básica.

Pires e Mendes (2020) realizaram outro estudo com vistas a caracterização de livros produzidos para uso em minicursos durante seminários de História da Matemática promovidos pela SBHMat entre 2001 e 2019, que foram elaborados para os Anos Finais do Ensino Fundamental, os quais foram classificados na tendência História para o Ensino da Matemática. Nesse sentido, a caracterização de livros de minicurso do Ensino Médio pode facilitar nas organizações didáticas e apoiar o professor nas aulas de Matemática. A caracterização dos livros de minicursos possibilita ao professor lê-lo e, a partir de sua leitura, reorganizar, adaptar ou criar práticas de investigação com seus alunos, utilizando-os como suporte, de modo a promover um ambiente de aprendizagem em que os alunos podem passar a compreender melhor a origem dos conhecimentos matemáticos tendo como base aspectos históricos implementados neles e ampliar substancialmente seus conhecimentos (PIRES; MENDES, 2020, p. 43).

Mediante essas implicações é que surgiu uma inquietação que, por sua vez, levou-nos a uma questão centralizadora em nosso estudo: Quais conteúdos de Matemática nos livros de minicursos do Ensino Médio possuem potencialidade didática para sala de aula? Para buscar responder à pergunta estabelecida foi necessário o empreendimento de um estudo relativo a importância do uso da história para o ensino da Matemática em sala de aula.

\section{SOBRE A HISTÓRIA PARA O ENSINO DA MATEMÁTICA}

Historicamente, a Matemática tem sido descrita como uma disciplina de extremo repúdio por muitos alunos, devido às elevadas dificuldades de assimilá-la. Na maioria das vezes, antes mesmo de se apropriarem de objetos matemáticos (conteúdos), são criados obstáculos que os impedem de ter afinidade com essa disciplina. Tal fato está condicionado principalmente ao ensino utilitário adotado pelas escolas que, de acordo com Pires (2019, p. 11), é o ensino voltado a operações matemáticas com procedimentos e algorítmicos ou similares, bem como demonstrações de teoremas para justificar a existência das propriedades 
matemáticas e a resolução de problemas matemáticos para dar explicação a determinada fórmula.

Tal realidade tem sido preocupante no âmbito escolar, uma vez que quando os alunos têm o primeiro contato com os conteúdos matemáticos, sentem aversão à disciplina, o que os leva a um condicionamento, por meio do qual costumam dizer que a Matemática é complicada, que é difícil (PIRES; FEITOSA, 2019, p. 245). D’Ambrosio (2002) advoga ser um comportamento restrito e uma previsão feita em relação à Matemática. Os alunos ingressam na escola apavorados com a disciplina, e apesar de já terem ouvido falar que a Matemática sempre está presente no cotidiano do ser humano, as limitações os impedem de romper com as barreiras e julgam-na um verdadeiro "bicho papão".

Muitos têm sido os estudos desenvolvidos no campo da Educação Matemática, que apontaram resultados profícuos, capazes de contribuir com o rompimento dos obstáculos conceituais e didáticos que têm pairado nas escolas e impedido os alunos de apreciarem a Matemática. Dentre as análises potencializadas no campo da Educação Matemática, destacamos as realizadas sobre História da Matemática, mais especificamente aquelas relativas à História voltada para o ensino de Matemática.

Dentre os especialistas que pesquisam sobre a História voltada para o ensino da Matemática, enfatizamos Iran Abreu Mendes. Em um artigo intitulado History for the Teaching of Mathematics: Transformation and Mobilization of Mathematical Knowledge for School, publicado em 2020, na Revista Pedagogical Research, Mendes (2020) estabelece argumentos que nos possibilitam conceber que a História capaz de mobilizar objetos de saberes matemáticos no ensino de Matemática trata da História do plural, das ideias matemáticas produzidas no tempo e no espaço.

Mendes (2020) afirma que a História da Matemática adequada para ser inserida no desenvolvimento conceitual dos alunos se refere diretamente ao aprimoramento epistemológico de ideias, definições e relações matemáticas ensinadas e aprendidas no Ensino Básico e no Ensino Superior, desde que os diferentes tipos de conhecimentos matemáticos emergentes dessas histórias sejam transformados e mobilizados pedagogicamente no exercício do ensino. Mais especificamente, refere-se às histórias relacionadas aos aspectos matemáticos em seu processo de criação, reinvenção e organização lógica, estabelecidas no tempo e no espaço, a fim de sistematizar soluções para problemas socioculturais, científicos e tecnológicos, em todos os períodos e lugares.

Tendo em vista a importância do uso da História da Matemática para o ensino dessa ciência, é necessário ao professor imprimir uma ação mediadora no processo e, por meio desta, 
abordar os conteúdos escolares de Matemática sob a forma de uma reinvenção didática na sala de aula, fundamentado conceitual e didaticamente pelo desenvolvimento histórico da disciplina.

A expressão reinvenção didática é uma noção conceitual estabelecida por Mendes (2017) em um artigo intitulado História para o Ensino da Matemática: uma reinvenção didática para a sala de aula, em que o autor propõe princípios e argumentos por meio dos quais evidencia, de forma clara e plausível, o tipo de história a que se refere, para ser tomada como base conceitual e didática do ensino de Matemática, ou seja, aquela que tem a vocação de despertar no aluno o espírito investigativo, ao utilizar ideias matemáticas produzidas no tempo e no espaço, em contextos socioculturais e que pode ser determinante na superação dos obstáculos encontrados no ensino-aprendizagem em Matemática (MENDES, 2017, p.145-166).

Dessa maneira, afirmamos que a História para o ensino da Matemática deve ser utilizada pelos professores em sala de aula em ações didáticas, de modo que os alunos, além de outras habilidades já mencionadas anteriormente, percebam que os conhecimentos matemáticos sempre estiveram e estão associados historicamente à cultura dos diversos grupos humanos.

A História da Matemática diz respeito aos diversos grupos humanos porque nossos saberes e fazeres são marcados por uma cultura que herdamos de nossos ancestrais. Em outras palavras, somos produtores de cultura e, ao mesmo tempo, produzidos a partir de culturas, pois há singularidade e particularidade em cada sujeito. E mesmo que cada um de nós esteja inserido no interior de um contexto cultural diverso, diferimos dos demais indivíduos por termos uma história individual que, por sua vez, nos é peculiar (FARIAS; MENDES, 2014, p. 16).

Seguindo na mesma esteira argumentativa, Mendes (2017) reitera que

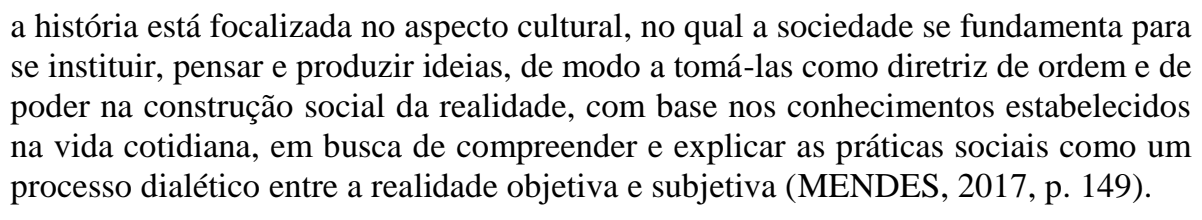

Ao tomarmos como referência essas reflexões sinalizadas por Mendes (2017) e por percebermos que são traçados argumentos em que é demonstrada a importância da cultura para a produção de estudos matemáticos, inferimos que os conhecimentos que recebemos é resultado de uma Matemática produzida no cotidiano pelos mais diversos grupos humanos que, por sua vez, deverão ser sistematizados no âmbito escolar, pois são saberes e fazeres praticados a partir das reais necessidades daquele grupo e que refletem nas culturas herdadas da sociedade que nos antecedeu.

Diante disso, é necessário aos professores incorporar na sala de aula conhecimentos matemáticos que foram produzidos historicamente pelos seres humanos nos contextos culturais, 
com vistas a ressignificar os conteúdos a serem ensinados aos alunos, pois, ao fazê-lo, os educadores perscrutarão por caminhos que poderão conduzir os educandos a uma motivação pela investigação na busca por respostas dos porquês matemáticos.

Os alunos, imersos nesse movimento, poderão incorporar saberes matemáticos que foram produzidos ao longo da história da humanidade e, nesse processo, poderão estabelecer um ambiente profícuo de aprendizagem, em que a História passará a ser caracterizada como um agente de cognição na Educação Matemática, conforme a noção conceitual estabelecida por Mendes (2006) no livro A história como um agente de cognição na Educação Matemática.

No referido livro há um capítulo intitulado A investigação histórica como agente de cognição matemática na sala de aula, no qual Mendes (2006) argumenta sobre a nocação conceitual ao apresentar princípios e argumentos contundentes a respeito da importância do uso da história como uma estratégia mediadora no desenvolvimento da ação cognitiva dos estudantes em sala de aula, a partir de prática investigativas que envolvam informações históricas. Neste capítulo são estabelecidos argumentos favoráveis à importância de os professores adotarem a História da Matemática como um agente de cognição, isto é, ao sobre o valor de lançarem mão do uso investigativo da História para o ensino da Matemática. Para o autor, por meio dessa prática os alunos passarão a desenvolver e incorporar para si habilidades por meio das quais estão implícitos a interação dialógica, o pensamento crítico, as tomadas de decisões, a autonomia, o processo de cognição matemática e, finalmente, a apropriação consciente dos objetos matemáticos.

Com base em Mendes (2015, 2017), Pires (2019) sugere que o professor deverá abordar conceitual e didaticamente o conteúdo de Matemática escolar utilizando as ideias matemáticas produzidas no passado (remoto ou recente), nos diversos contextos socioculturais, de modo a despertar, além do que foi mencionado, o pensamento criativo por meio da prática de investigação (MENDES, 2009, 2015). Mas, para isso, é necessário que professores se autodesafiem para incorporar práticas inovadoras, por meio de um ensino que se diferencie do que vem sendo praticado ${ }^{5}$, pois defendemos, favoravelmente, que o uso de fontes históricas com potencialidade didática possibilitará, dentre outros aspectos, reatar o nó górdio que tem separado a relação entre os conhecimentos matemáticos e a história do seu desenvolvimento.

\footnotetext{
${ }^{5} \mathrm{O}$ sentido atribuído à expressão ensino diferenciado não diz respeito a um ensino mecânico, desvinculado das práticas socioculturais, mas se trata daquele que seja capaz de preconizar aspectos histórico-culturais da Matemática, em que a adoção de fontes históricas em sala de aula poderá propiciar um ambiente de aprendizagem no qual os alunos possam compreender o desenvolvimento conceitual dos conteúdos matemáticos e assim despertar a curiosidade, a motivação cognitiva e a criatividade no processo mediado pelo professor.
} 
A expressão reatar o nó górdio é utilizada Bruno Latour (2013) no livro Jamais somos modernos, em que o autor argumenta sobre a importância de sempre renovarmos os nós górdios que nos impedem de compreender que natureza e cultura são interconectadas, que não devem ser separadas, que somos parte indissociável de ambas, pois vivemos pela cultura, na natureza. Nesse sentido, somos híbridos, acoplados em um emaranhado de saberes e fazeres culturais herdados daqueles que nos antecederam.

Nesse aspecto, na condição de professores que ensinam Matemática, é necessário desatarmos os nós górdios que nos condicionam a adotar como diretriz um ensino único e simplesmente utilitário, que separa o social do cultural, a Matemática de sua história conceitual. As ações didáticas assentadas no uso da história para o ensino da Matemática têm apontado contribuições para o desenvolvimento da motivação cognitiva dos alunos em torno da aprendizagem matemática.

Pires (2019) pleiteia que uma das maneiras de colocarmos em prática o ensino que busca o híbrido consiste no uso de fontes históricas que deixam claro o desenvolvimento conceitual dos conteúdos matemáticos produzidos historicamente, sem perder de vista a relação inseparável com a cultura. Esse vínculo está ancorado nas três caraterísticas da História para o ensino da Matemática: história com aspectos formativos, informativos e utilitários, segundo apresentado na Figura 1 (MENDES, 2017, p. 156).

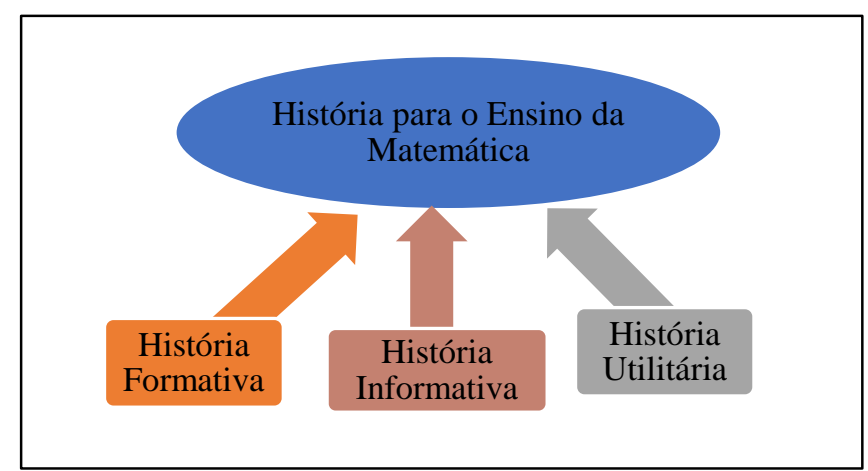

Figura 1 - Composição de um modelo didático.

Fonte: Pires (2019, p. 10), com base em Mendes (2015).

Com base nessas três características, segundo mencionadas na Figura 1, Pires (2019), apoiado em Mendes (2015) esclarece que a história formativa refere-se sobre o que foi tratado a respeito do desenvolvimento epistemológico das pesquisas que abordam algum conceito matemático, de maneira que se perceba a forma como os matemáticos produziam matemáticas no tempo e no espaço, e a forma como esses conhecimentos vieram se desenvolvendo e se transformando de acordo com as reais necessidades da humanidade, na medida em que a sociedade se reinventa. 
Ainda com base em Mendes (2015), Pires (2019) menciona que a história informativa se refere a menos ou pouco desenvolvimento conceitual relativo ao conceito matemático, em que as informações versam sobre nome de determinados matemáticos importantes em determinada época da história, datas, suas narrativas, bem como locais pelos quais esses matemáticos trabalharam. A esse tipo de história, reiteramos que o foco não é a configuração fundamental a respeito do desenvolvimento dos conceitos, propriedades e relações matemáticas.

De acordo com Pires (2019), baseado em Mendes (2015), a história utilitária - é a história que se refere ao desenvolvimento das operações Matemáticas com procedimentos e algorítmicos ou similares, bem como demonstração de teoremas para justificar a existência das propriedades Matemáticas e a resolução de problemas matemáticos, com vista a dar explicação à determinada fórmula Matemática.

Ao fazer esse movimento, é possível instituir um ambiente de aprendizagem com mais significado, o que contribui com o rompimento de um ensino linear compartimentalizado para um ensino que incita a criatividade nos alunos. Além disso, o professor, ao legitimar o uso da História no ensino de Matemática, estará contribuindo para a reorientação do currículo escolar.

Mendes (2017) sustenta que a reorientação curricular deve sugerir a promoção de discussões sobre as possibilidades didáticas e conceituais da investigação histórica em sala de aula. E isso pode ser uma aposta para que, no futuro, tenhamos alunos mais autônomos no que diz respeito à busca de sua própria aprendizagem acerca do conhecimento matemático que lhe for exigido em qualquer instância da vida.

Talvez essa reorientação propicie a efetivação de um diálogo entre os conteúdos escolares abordados nas salas de aula e as práticas socioculturais e científicas definidas no passado e no presente, na forma de um processo de estímulo ao exercício de criatividade matemática por parte do professor em relação ao aluno, de modo a viabilizar a incorporação desse exercício pelo educando (MENDES, 2017). É nesse sentido que o professor estará se autodesafiando, tendo em vista a adoção da História no ensino de Matemática para que efetivamente possa estimular os alunos a estudar os conteúdos matemáticos.

\section{SOBRE OS PROCEDIMENTOS METODOLÓGICOS}

Para o desenvolvimento deste estudo, delineamos um instrumento de análise formado por vários aspectos essenciais, a partir dos estudos relativos à ciência da documentação. Os elementos compostos para a estruturação do instrumento de análise foram: título do livro; nome 
do autor que elaborou o livro; ano de publicação; editora; cidade e instituição onde foi realizado o evento; conteúdo principal abordado; conteúdo secundário tratado; nível de ensino em que pode ser utilizado o livro; tipo de abordagens que foram enfocadas; características de cada atividade elaborada. Contemplamos, ainda, no instrumento de análise, elementos como contribuições do livro como recurso didático, ou seja, o potencial didático (BARROS; MENDES, 2017, p. 140) que o livro possui e a tendência HEnM, a qual foi apreciada para a realização do estudo, consoante exibido no Quadro 1:

\begin{tabular}{l} 
Elementos que compôs o instrumento para análise dos livros de minicursos \\
\hline Título: Título do livro de minicurso dos anos finais do Ensino Fundamental. \\
\hline Autor (a): responsável pela elaboração do livro de minicurso. \\
\hline Ano: Ano em que o livro de minicurso foi publicado. \\
\hline Cidade: Cidade do SNHM onde o livro de minicurso foi ofertado. \\
\hline Conteúdo (s) primário (s): Álgebra, Aritmética, Geometria e Trigonometria. \\
\hline $\begin{array}{l}\text { Conteúdos secundários: Conteúdo(s) tratado no livro de minicurso derivado(s) } \\
\text { do(s) conteúdo(s) primário(s). }\end{array}$
\end{tabular}

Nível: É o livro de minicurso que trata dos conteúdos para os níveis de ensino (Fundamental, Médio e Superior).

Abordagem: É a análise das abordagens tratadas no livro de minicurso para que seja classificado nas tendências da História da Matemática.

Atividades: É a verificação da existência de atividades didáticas no livro de minicurso que podem ser utilizadas didaticamente para auxiliar o professor em sua prática docente.

Característica das atividades: É a realização da caracterização de cada atividade intrínseca ao livro de minicurso, com vistas a compreender até que ponto são determinantes ou não para serem implantadas em sala de aula.

Contribuições para o professor: É verificar se no livro de minicurso há contribuições à utilização pelo professor como auxílio em sua prática docente.

Tendência: É a preconização dos elementos anteriormente preenchidos e uma análise pormenorizada sobre o livro de minicurso, levando-se em consideração todas as abordagens defendidas por Mendes $(2014,2015)$, para então verificar se se referem à HEpM ou à HEnM ou à HEdM.

Quadro 1 - Descritor dos conteúdos dos livros de minicursos para o Ensino Médio.

Fonte: Mendes e Pires (2020, p. 06).

De acordo com as informações dispostas no Quadro 1, sobre os elementos que compuseram o instrumento de análise para a realização do estudo dos livros de minicursos da SBHMat, que foram publicados nos SNHM, conferimos destaque aos que apresentavam potencial didático. Em outras palavras, centramos nosso olhar sobre aqueles que podem ser mobilizados em sala de aula para subsidiar a prática do professor. Aqueles cujas abordagens se canalizaram em aspectos teórico-epistemológicos e da História da Educação Matemática foram agrupados como outros, os quais serão objeto de estudos posteriores. 
Iniciamos o procedimento com o preenchimento do instrumento de análise para cada livro da HEnM identificado. Ao completá-los, selecionamos aqueles que abordavam os temas principais da Matemática, bem como os conteúdos principais focalizados do Ensino Médio (BARROS; MENDES, 2019, p. 139-150). Posteriormente, realizamos a descrição dos conteúdos matemáticos apresentados. Por meio de nossas primeiras reflexões sobre o desenvolvimento do estudo, compreendemos que, concretamente, havia a necessidade de investir na procura de possíveis potenciais para o ensino de Matemática que pudessem ser discernidos nesses materiais de minicursos (BARROS; MENDES, 2019, p. 406), pois a quantidade de livros com potencial didático foi positiva e pode ser utilizada pelos professores sem que seja indispensável passar pelo processo de readaptação.

Tomando como base a utilização do descritor de análise, utilizamos a classificação quantitativa dos livros de minicursos nas três tendências da História da Matemática realizado por Pires e Mendes (2020), conforme apresentadas no Quadro 2 a seguir.

\begin{tabular}{|c|c|c|c|c|}
\hline Período & Quantidade & HEpM & HEnM & HEdM \\
\hline $2001-2017$ & 101 & 35 & 47 & 19 \\
\hline
\end{tabular}

Quadro 2: LMs nas tendências em História da Matemática Fonte: PIRES, L. S.; MENDES, I. A.

Segundo Pires e Mendes (2020), do total de 101 livros de minicursos publicados nos seminários ocorridos em várias cidades do Brasil no período compreendido entre 2001 e 2017, $35 \%$ trataram da HEpM. As abordagens estiveram relacionadas vida e obra de matemáticos e o desenvolvimento de suas ideias matemáticas, bem como o desenvolvimento da área em pauta enquanto conteúdo cientifico, (MENDES, 2015).

De acordo com Pires e Mendes (2020), os 47\% dos livros de minicurso da HEnM trataram de fontes históricas voltadas a fins didáticos que podem ser utilizadas para o ensino de matemática escolar, bem como para orientações didáticas e para formação de professores que ensinam Matemática, (MENDES, 2019, p. 36).

Em relação aos livros de minicursos classificados na tendência HEdM, 19\% trataram de temas de estudos históricos, sobre uma época determinada, um grupo específico, relações da Matemática com outras áreas do conhecimento, aplicações da História da Matemática, livros didáticos, sobre o desenvolvimento de produções acerca da História da Matemática, pesquisas sobre as instituições em que renomados matemáticos trabalharam, biografias de matemáticos para entender o movimento histórico-cultural da forma como os conhecimentos matemáticos 
eram desenvolvidos em determinada época nos contextos socioculturais e, cursos de Matemática, (MENDES, 2019, p. 32).

\section{SOBRE OS CONTEÚDOS DO ENSINO MÉDIO IDENTIFICADOS}

Nesta seção, focalizamos livros de minicursos publicados nos SNHM cujas abordagens apontadas se concentraram nos conteúdos referentes ao Ensino Médio, que podem ser empreendidos em sala de aula para subsidiar os professores em sua prática pedagógica. Assim, comentaremos a respeito daqueles que trataram de aspectos relativos à História para o ensino da Matemática, que, por sua vez, possuem potencial didático a ser utilizado pelos educadores no exercício da docência, cujo número representativo é exposto no Quadro 3.

\begin{tabular}{|c|c|c|c|}
\hline Período & Quantidade & HEnM & Outros \\
\hline 2001-2017 & 101 & 47 & 54 \\
\hline
\end{tabular}

Em virtude da intensificação do movimento em torno da área de pesquisa História da Matemática, no ano de 1999, cria-se a Sociedade Brasileira de História da Matemática (SBHMat). E, no ano de 2001, inicia-se o projeto de publicação de livros de minicursos para educadores dos diferentes níveis de ensino, como do Ensino Fundamental I, Ensino Fundamental II, Ensino Médio, Ensino Superior e para a Formação de Professores.

O Quadro 3 apresenta informações referentes aos minicursos publicados a partir de 2001, pois, no que concerne aos três primeiros Seminários Nacionais de História da Matemática (SNHM), que aconteceram em Recife/PE (1995), Águas de São Pedro/SP (1997) e Vitória/ES (1999), identificamos que ocorreram minicursos, mas não foram publicados livros com o material produzido para as ações. Somente a partir do IV SNHM, realizado na cidade de Natal (Rio Grande do Norte), na Universidade Federal de Rio Grande do Norte (UFRN) em 2001, foi publicada a primeira coleção História da Matemática para Professores, composta por nove livros de minicursos e editada por John Andrew Fossa (MENDES; PIRES; MARQUES, 2019).

Os 101 livros de minicursos apresentados anteriormente possuem diversas abordagens caracterizadas por vários resultados de pesquisas. Desse número, $47 \%$ trataram de informações históricas, orientações pedagógicas para o uso da História da Matemática e formação de professores de Matemática a partir de origens históricas, sobretudo aquelas que se utilizam 
dessas fontes para formar professores no que tange às práticas de ensino ligadas à História da Matemática, aspectos que são relativos à HEnM. Segundo Mendes (2019), esses textos focaram na História da Matemática como princípios de informações a serem utilizadas para o ensino de Matemática escolar, assim como para a elaboração de atividades educativas.

O número de livros de minicursos com fins pedagógicos foi significativo, o que nos permitiu perceber que as pesquisas realizadas para tal fim estão em crescimento. Em termos quantitativos, constatamos a existência de muitos materiais com propostas didáticas motivadoras, baseadas em fontes históricas, que podem ser destinadas ao professor que leciona para alunos do Ensino Médio, em conformidade com o que se profere no Quadro 4.

\begin{tabular}{|c|c|c|}
\hline HEnM & Número de livros de Minicursos do Ensino Médio & Outros \\
\hline 47 & 9 & 38 \\
\hline & $\begin{array}{c}\text { Quadro 4 - Livros de Minicursos para o Ensino Médio. } \\
\text { Fonte: Elaborado pelos autores a partir do material da pesquisa, } 2019 .\end{array}$ \\
\hline
\end{tabular}

Em conformidade com o número de livros de minicursos identificados, $19 \%$ foram aqueles que podem ser destinados aos professores que atuam no Ensino Médio, pois neles são apresentadas propostas didáticas que abordam diversos conteúdos de Matemática para esse nível de ensino, e desmembramentos de estudos futuros para esse público, abrindo-se à possibilidade de manifestar a capacidade de alocar os alunos para um ensino-aprendizagem baseado na pesquisa e investigação histórica, de modo a conduzir o educando a se apropriar do desenvolvimento conceitual das questões matemáticas que foram se transformando no tempo e no espaço, de acordo com as necessidades humanas.

Segundo os resultados obtidos neste estudo, o número de livros de minicursos referentes à tendência HEnM é significativo. De acordo com Mendes, Pires e Marques (2019), os aspectos que caracterizam os minicursos nessa tendência se relacionam ao fato de que eles apresentam propostas didáticas concretas para as aulas de Matemática (atividades orientadas propostas), indicações didáticas para professores em formação, e, também, redirecionam didaticamente as práticas dos professores de Matemática no planejamento de suas aulas ou quando necessitarem de fontes históricas para encaminhamentos e/ou esclarecimentos a respeito de como usar a História da Matemática como fio condutor em suas aulas de Matemática.

Evidenciamos, mediante este estudo, que os $81 \%$ dos livros da tendência mencionada anteriormente pode servir como uma ferramenta didática para auxiliar o professor em sua prática docente, pois ficou patente que possuem propostas didáticas concretas para a sala de 
aula, além de apresentarem orientações para o professor e propostas pedagógicas para a formação docente. A partir desse percentual, ficou em destaque o número de livros de minicursos que trataram de conteúdos relativos aos quatro temas da Matemática, segundo manifestado no Quadro 5.

\begin{tabular}{|c|c|c|c|c|c|c|c|c|c|}
\hline \multirow{2}{*}{ Nível de Ensino } & \multicolumn{9}{|c|}{ Anos em que Ocorreram os Seminários } \\
\hline & 2001 & 2003 & 2005 & 2007 & 2009 & 2011 & 2013 & 2015 & 2017 \\
\hline Ensino Médio & - & 1 & 2 & 1 & 3 & 1 & 1 & - & - \\
\hline
\end{tabular}

Em concordância com os dados do Quadro 5, compreendemos que no evento ocorrido na cidade de Natal (Rio Grande do Norte), na Universidade Federal de Rio Grande do Norte (UFRN), em 2001, não houve livros de minicursos com abordagens para o Ensino Médio. Já no evento ocorrido em 2003, na Universidade Estadual Paulista Júlio de Mesquita Filho UNESP/Rio Claro, na cidade de Rio Claro/SP, identificamos um livro de minicurso, cujo tema tratado refere-se à Geometria, com enfoque para Simetria, área de círculo, trapézio e volume da pirâmide.

No que concerne ao evento transcorrido em 2005, na Universidade de Brasília - UnB, em Brasília, no Distrito Federal, dois livros de minicursos discutem temas como Geometria, focalizado em medidas geométricas, e Trigonometria, cujas análises estão centralizadas em medidas de graus e relações de semelhança no triângulo retângulo. Em relação ao evento ocorrido em 2007, em Guarapuava/Paraná, na Universidade Estadual do Centro-Oeste (UNICENTRO), um livro versou sobre o tema Álgebra, cujas interpretações foram direcionadas ao conteúdo equações algébricas.

No evento ocorrido em Belém do Pará, na Universidade da Amazônia (UNAMA), no ano de 2009, foram produzidos para publicação três livros de minicursos do Ensino Médio, que podem ser utilizados como recurso didático pelos professores, com vistas a potencializar o ensino-aprendizagem dos alunos desse nível de ensino. Os livros aludem temas como Álgebra - cujos enfoques são sobre equações do terceiro e quarto graus, números complexos e produtos notáveis; Aritmética - em que se discorre sobre o conteúdo referente à análise combinatória e Geometria - com perspectivas voltadas exclusivamente a polígonos regulares, planificação de sólidos geométricos, reta, plano, volume de esfera, cone, ponto médio, segmento de reta e cônicas. Sobre o evento ocorrido em Aracaju/SE, na Universidade Federal de Sergipe (UFS), 
no ano de 2011, foi identificado um livro de minicurso, que tratou do tema Álgebra, com abordagem voltada a funções, mais especificamente, função afim, quadrática e exponencial.

No seminário ocorrido em Campinas/SP, na Universidade Estadual de Campinas (UNICAMP), em 2013, reconhecemos um livro de minicurso que tratou do tema Geometria, cujos conteúdos foram resoluções de problemas geométricos, polígonos de Platão e Euler. Em relação ao acontecimento ocorrido em Natal/RN, na Universidade Federal do Rio Grande do Norte (UFRN), em 2015, não houve livros de minicursos que versaram sobre conteúdos para o Ensino Médio, uma vez que os temas discutidos foram relativos a outros níveis de ensino que não são o foco deste estudo. De maneira análoga, no evento sucedido em Itajubá/MG, na Universidade Federal de Itajubá (UNIFEI), em 2017, não identificamos livros de minicurso pertinente a esse nível de ensino.

Com a relação dos títulos dos livros de minicursos que trataram de conteúdos matemáticos do Ensino Médio, apresentamos no Quadro 6 tais informações a esse respeito.

Livros de Minicursos do Ensino Médio (2001-2017)
2003 - Explorando a Geometria por meio da História da Matemática e da
Etnomatemática.
2005 - O Conhecimento Matemático na Época das Navegações.
2005 - História, Etnomatemática e Prática pedagógica.
2007 - Resolução de Equações Algébricas por Radicais.
2009 - Uma Incursão em alguns tópicos da História da Geometria.
2009 - Métodos Históricos para Resolução Algébrica de Equações.
2009 - Algumas observações sobre a característica de Euler. Uma introdução de
elementos da História da Matemática no Ensino Médio.
2011 - Uma introdução para o estudo histórico da Geometria Analítica Plana.
2013 - A Matemática no Ensino Fundamental: uma abordagem didática centrada nos
problemas com motivação na história.

Quadro 6 - Relação dos Livros de Minicursos do Ensino Médio identificados. Fonte: Elaborado pelos autores a partir do material da pesquisa, 2019.

No Quadro 6 observamos nove livros de minicursos com potencial didático que podem ser mobilizados pelos professores que trabalham com esse nível de ensino, com vistas a serem implementados em sala de aula para potencializar o ensino de Matemática, pois os assuntos são amplos, o que, de fato, favorecerá tanto o ensino-aprendizagem dos alunos como também impactará positivamente na formação de professores, ao incorporarem as sugestões didáticas instituídas por meio desse material.

A relação dos livros de minicursos do Ensino Médio que estabelecemos no Quadro 6 pode possibilitar aos professores utilizar as ferramentas desse nível de ensino como recurso didático de maneira mais fácil, haja vista que, ao terem acesso aos títulos desses livros, poderão fazer download do material ao acessar o CREPHIMat, por meio do link que mencionamos no 
início deste artigo, e/ou, a partir de seus planejamentos, poderão orientar os alunos à realização de pesquisas sobre o aparato disponibilizado em ambiente virtual, com o intuito de incorporarem para si habilidades por meio das quais poderão emergir a curiosidade, a motivação cognitiva, entre outras possibilidades durante o desenvolvimento da investigação, pois esta exige leitura e imersão, e é nesse processo que o ensino-aprendizagem se fará presente.

\section{REFLEXÕES SOBRE O ESTUDO}

Este estudo representa uma possibilidade de contribuir com o ensino de Matemática na Educação Básica, haja vista que por meio do agrupamento em que organizamos os livros de minicursos, identificamos aqueles que podem ser destinados exclusivamente aos alunos do Ensino Médio, os quais poderão facilitar as organizações didáticas dos professores que lecionam nesse nível de ensino. Além disso, a descrição dos conteúdos de Matemática contidos nesses materiais poderá favorecer aos professores lançar mão dessa ferramenta didática com vistas a potencializar seu fazer pedagógico.

Nesse contexto, acreditamos que a maneira como organizamos a referida ferramenta será um ganho, pois o intuito é que professores possam ter acesso a esse material com maior facilidade. Assim, cremos que nosso objetivo foi alcançado, em virtude de que, para a materialização do estudo, tomamos como parâmetros conceitos basilares que sustentaram a nossa pesquisa e potencializaram as discussões sobre a importância indispensável do potencial didático das propostas de atividades nos livros de minicursos.

Com base nas atividades estabelecidas no material investigado, um dos aspectos que consideramos de maior relevância são as propostas de atividades segundo fontes históricas. Sugerimos que elas poderão servir como ferramenta pedagógica e didática para a sala de aula, nas ações dos professores que ensinam Matemática.

Portanto, para que essa ação se materialize, o professor deverá adotá-la como recurso didático em sua prática docente, com vistas a enriquecer os conhecimentos matemáticos no Ensino Médio, e, nessa técnica, impactar positivamente o estímulo dos alunos para que, no processo ensino-aprendizagem, possam ocorrer a curiosidade, a motivação cognitiva e as habilidades que estiverem subjacentes, uma vez que a história adotada para ensinar Matemática, instituída nos livros de minicursos, se utilizada pelos professores de maneira investigativa, poderá estabelecer um processo criativo nos alunos, em virtude de seu potencial didático significativo. 
Outras considerações demonstram nossa aposta de que, no processo de apropriação desse material, e ao incorporar as ideias sobre o desenvolvimento dos conceitos históricos voltados ao ensino de Matemática, os professores, mesmo que inconscientemente, estarão sendo formados, pois a Formação de professores acontece também nesse movimento, e, sobretudo, durante o planejamento, no sentido de esse profissional se autodesafiar a trabalhar o ensino por investigação histórica. Para futuros estudos, acreditamos também na importância da pesquisa a partir do uso dessa ferramenta pedagógica no ensino, bem como a relação de complementaridade em relação ao livro didático vigente que é utilizado em sala de aula no Ensino Médio.

\section{AGRADECIMENTOS}

Este artigo tem o apoio da Coordenação de Aperfeiçoamento de Pessoal de Nível Superior - Brasil (CAPES), e se classifica como uma produção gerada nos projetos de pesquisas vinculados a programas de pós-graduação em níveis de mestrado e doutorado. Agradeço ao Conselho Nacional de Desenvolvimento Científico e Tecnológico (CNPq), pela concessão de uma bolsa de estudos para fomento de minhas pesquisas na Pós-Graduação em Educação Matemática.

\section{REFERENCIAS}

BARROS, R. J. A. R.; MENDES, I. A. Descrição dos conteúdos de ensino superior presentes nas teses em história e epistemologia da matemática (1990-2010). Cocar: Revista do Programa de Pós-graduação em Educação da Universidade do Estado do Pará, v. 13, n. 25, abr. 2019. Disponível em: http://páginas.uepa.br/seer/index.php/cocar. Acesso em: 14 abr. 2020 .

BARROS, R. J. A. R.; MENDES, I. A. Dissertações e teses em História e Epistemologia da Matemática: contribuições para a abordagem da Geometria Espacial no Ensino Médio.

Principia: Revista de Divulgação Científica e Tecnológica do Instituto Federal da Paraíba, n. 37, nov. 2017. Disponível em: https://periódicos.ifpb.edu.br/index.php/principia. Acesso em: 16 abr. 2020.

BERGER, Peter.; LUCKMANN, Thomas. A construção social da realidade. 34. ed. Tradução de Floriano de Souza Fernandes. Petrópolis-RJ: Vozes, 2014.

BONJIOVANNI, Vincenzo. Uma Incursão em alguns tópicos da História da Geometria. Belém, PA, SBHMat (preprint), 2009. Disponível em: <http://www.crephimat.com>. Acesso em: 7 de out., 2020.

BRANDEMBERG, João Cláudio. Métodos Históricos para Resolução Algébrica de 
Equações. Belém, PA, SBHMat (preprint), 2009. Disponível em:

<http://www.crephimat.com>. Acesso em: 7 de out., 2020.

CAVALARI, Mariana Feiteiro; MARTINS, César Ricardo Peon. Uma introdução para o estudo histórico da Geometria Analítica Plana. Aracajú - SE, SBHMat (preprint), 2011. Disponível em: <http://www.crephimat.com>. Acesso em: 7 de out., 2020.

D'AMBROSIO, U. Etnomatemática: elo entre as tradições e a modernidade. 2. ed. Belo Horizonte: Autêntica, 2002.

FARIAS, Carlos Aldemir; MENDES, Iran Abreu. As culturas são as marcas das sociedades humanas. In: MENDES, Iran Abreu; FARIAS, Carlos Aldemir (Orgs.). Práticas

Socioculturais e Educação Matemática. 1. ed. São Paulo: Livraria da Física, 2014.

GASPAR, Terezinha Maria; MAURO, Suzeli. Explorando a Geometria através da História da Matemática e da Etnomatemática. Rio Claro, SP, SBHMat (preprint), 2003. Disponível em: <http://www.crephimat.com>. Acesso em: 7 de out., 2020.

GONÇALVES, Francisco Djnnathan da Silva. História da Educação Matemática no Brasil: Contribuições das pesquisas para professores da Educação Básica. 2012. Dissertação (Mestrado em Ensino de Ciências Naturais e Matemática). Universidade Federal do Rio Grande do Norte, UFRN, Natal (RN).

LATOUR, Bruno. Jamais Fomos Modernos. 3. ed. São Paulo: Editora 34, 2013.

MARTINES, Mônica de Cássia Siqueira. Algumas observações sobre a característica de Euler. Uma introdução de elementos da História da Matemática no Ensino Médio. Belém, PA, SBHMat (preprint), 2009. Disponível em: 〈http://www.crephimat.com>. Acesso em: 7 de out., 2020.

MELLO, Albimar Gonçalves. Recorte dos produtos educacionais em História no Ensino da Matemática e em Didática da Matemática a partir das Dissertações e Teses defendidas no Brasil entre 1990-2010. 2012. Dissertação (Mestrado em Ensino de Ciências Naturais e Matemática). Universidade Federal do Rio Grande do Norte, UFRN, Natal (RN).

MELO, Severino Barros de. A Matemática no Ensino Fundamental: uma abordagem didática centrada nos problemas com motivação na história. Campinas, SP, SBHMat (preprint), 2013. Disponível em: 〈http://www.crephimat.com>. Acesso em: 7 de out., 2020.

MENDES, Iran Abreu. A investigação histórica como agente de cognição matemática na sala de aula. In: MENDES, Iran Abreu; FOSSA, John Andrew; VALDÉS, Juan E. Nápoles. A história como um agente de cognição na educação Matemática.1. ed.: Porto Alegre: Sulina, 2006.

MENDES, Iran Abreu. Investigação histórica no ensino da Matemática. 1. ed. Rio de Janeiro: Ciência Moderna, 2009.

MENDES, Iran Abreu. Pesquisas em história da educação matemática no Brasil em três dimensões. Quipu, México, v. 14, n. 1, jan.-abr., 2012, p. 69-92. 
MENDES, Iran Abreu. Cartografias da produção em História da Matemática no Brasil: um estudo centrado nas dissertações e teses defendidas entre 1990-2010. Relatório de Pesquisa (Bolsa produtividade CNPq). Universidade Federal do Rio Grande do Norte, Natal, 2014.

MENDES, Iran Abreu. História da Matemática no Ensino: entre trajetórias profissionais, epistemologias e pesquisas. 1. ed. São Paulo: Livraria da Física, 2015.

MENDES, I. A. História para o ensino da matemática: uma reinvenção didática para a sala de aula. Cocar: Revista do Programa de Pós-graduação Educação em Educação da Universidade do Estado do Pará, n. 3, jul. 2017. Disponível em: http://páginas.uepa.br/seer/index.php/cocar. Acesso em: 14 abr., 2020.

MENDES, I. A. História para a Educação Matemática: apontamentos sobre as pesquisas brasileiras. Exitus, v. 9, n. 2, p. 26-50, jun., 2019. Disponível em:

https://doi.org/10.24065/2237-9460.2019v9n2ID853. Acessso em: 07 de out. 2020.

MENDES, I. A. History for the Teaching of Mathematics: Transformation and Mobilization of Mathematical Knowledge for School. Pedagogical Research, v. 5, n 3, jul. 2020.

Disponível em: https://doi.org/10.29333/pr/8284. Acesso em: 03 de jun., 2020.

MENDES, Iran Abreu. Centro Brasileiro de Referência em Pesquisa sobre História da Matemática. CREPHIMat. Disponível em: 〈http://www.crephimat.com>. Acesso em: 7 de out., 2020.

MENDES, I. A.; PIRES, L. S. História da Matemática do Ensino Fundamental nos Livros de Minicursos da SBHMat (2001-2017). RPD: Revista Prática Docente, v. 4. n. 1. jan./jun. 2020. Disponível em: http://periodicos.cfs.ifmt.edu.br. Acesso em: 5 abr., 2020.

MENDES, I. A.; PIRES, L. S.; MARQUES, R. M. S. História da Matemática para o Ensino Fundamental II nos Livros de Minicursos dos SNHM (2001-2017). In: SINEPEM SIMPÓSIO NACIONAL SOBRE O ENSINO E PESQUISA DA MATEMÁTICA NO CONTEXTO DA EDUCAÇÃO, CIÊNCIA E TECNOLOGIA, 2019, Belém. Anais... Belém, PA: SINEPEM. Disponível em:

http://sinepem.sbempara.com.br/login/files/ANAISSINEPEM.pdf. Acesso em: 7 abr. 2020.

MOREY, Bernadete; MENDES, Iran Abreu. Conhecimentos matemáticos na época das navegações. Brasília, DF, SBHMat (preprint), 2005. Disponível em:

<http://www.crephimat.com>. Acesso em: 7 de out., 2020.

PIRES, L. S. História para o ensino de sistema de numeração decimal em teses e dissertações (1990-2018). REMATEC: Revista de Matemática, Ensino e Cultura, ano 14, n. 32, p.193211, 2019. Disponível em: https://doi.org/10.37084/REMATEC.1980-3141.2019.n32.p193211.id212. Acesso em: 9 abr., 2020.

PIRES, L. S.; FEITOSA, D. S. Aprendendo Função do $1^{\circ}$ Grau a partir de Narrativas de Produtores de leite bovino. In: RITTER, D.; SOARES, G. O. (Orgs.). Ensino de Matemática em foco pesquisas, relatos e propostas. 1. ed. Rio de Janeiro: Dictio Brasil, 2019. Disponível em: doi.org/10.35417/978-85-92921-51-4. Acesso em: 20 jan., 2020. 
PIRES, L. S; MENDES, I. A. História da matemática do ensino fundamental nos livros de minicursos da SBHMat (2001-2017). Revista Prática Docente. v. 5, n. 1, p. 28-44, jan/abr 2020. Disponível em: http://dx.doi.org/10.23926/RPD.2526-2149.2020.v5.n1.p28-44.id575. Acesso em: 08 de set., 2020.

SCANDIUZZI, Pedro Paulo. História, Etnomatemática e Prática pedagógica. Brasília, DF, SBHMat (preprint), 2005. Disponível em: 〈http://www.crephimat.com>. Acesso em: 7 de out., 2020.

TEIXEIRA, Marcos Vieira; MARTINS, César Ricardo Paulo. Resolução de Equações Algébricas por Radicais. Guarapuava, PR, SBHMat (preprint), 2007. Disponível em: <http://www.crephimat.com>. Acesso em: 7 de out., 2020.

Submetido em: 27 de junho de 2020 .

Aprovado em: 02 de outubro de 2020. 